\title{
Needle Stick Injuries among Health Care workers in a Multispecialty Hospital: A Retrospective Study
}

\author{
Ramakrishna Pai Jakribettu ${ }^{1,2 *}$, Ovine Loyster D'souza ${ }^{2,3}$, Valerian Sudeep Pinto ${ }^{2,3}$, \\ Vidya Rao Surlu ${ }^{2,4,5}$, Rekha Boloor ${ }^{1,2}$ and Manjeshwar Shrinath Baliga ${ }^{6}$ \\ ${ }^{1}$ Department of Microbiology, ${ }^{2}$ Hospital Infection Control Unit, ${ }^{3}$ Department of Psychiatric \\ Nursing, Father Muller College of Nursing, Mangalore, Karnataka, India 575002 \\ ${ }^{4}$ Department of Hospital Administration, ${ }^{5}$ Quality Control Department, Father Muller Medical \\ College Hospital, Mangalore, Karnataka, India 575002 \\ ${ }^{6}$ Father Muller Research Centre, Father Muller Road, Kankanady, Mangalore, Karnataka, India \\ *Corresponding author
}

\begin{tabular}{|c|c|}
\hline & A B S T R A C T \\
\hline $\begin{array}{l}\text { Ke e w o o d s } \\
\text { Needle Stick } \\
\text { Injuries, Health } \\
\text { Care Workers. }\end{array}$ & $\begin{array}{l}\text { In developing countries, Occupation health and safety is not given priority. The Needle } \\
\text { stick Injuries (NSI) are among the incidents which risk the safety of Health Care workers } \\
\text { in the hospital and healthcare setup. The purpose of this study was to assess the prevalence } \\
\text { of NSI's in a tertiary care teaching hospital. A total of } 70 \text { NSI's were reported and studied } \\
\text { from January to December 2014. Needle stick injuries were more common among doctors } \\
\text { and nurses and majority of the NSI's were reported during blood collection }(27 \%)\end{array}$ \\
\hline Article Info & followed by invasive procedures $(21 \%)$. The incidence was higher in the trainees' \\
\hline $\begin{array}{l}\text { Accepted: } \\
04 \text { April } 2017 \\
\text { Available Online: } \\
10 \text { May } 2017\end{array}$ & $\begin{array}{l}\text { especially in their initial training period. The wards }(41 \%) \text {, followed by emergency room } \\
\text { and the intensive care units }(25 \%) \text {. Regular training on the cause, consequences and } \\
\text { prevention of NSI to the health care professionals, including trainee may help in reducing } \\
\text { the incident. }\end{array}$ \\
\hline
\end{tabular}

\section{Introduction}

Health care professionals (HCP) are at greater risk of exposure to the blood and body fluids. Blood borne pathogens are transmitted through accidental needle and/or sharps injury especially Hepatitis B virus (HBV), Hepatitis $\mathrm{C}$ virus (HCV) and Human Immunodeficiency Virus (HIV) (National Institute for Occupational Safety and Health, 1999). Hepatitis B virus (HBV) transmission rate by NSI is estimated to be around 33.3\%, followed by Hepatitis C virus (3.3\%) and HIV (0.3) (Robson et al., 2012).
The World Health Organization has estimated that exposure to sharps in the workplace accounts for $40 \%$ of infections with HBV and $\mathrm{HCV}$ and $2-3 \%$ of HIV infections among health care workers. All categories of workers in the healthcare setup are at risk of NSI, which include doctors, nurses, laboratory personnels, housekeeping workers and biomedical waste handlers.

Among health care professional's nurses and surgeons, are at higher risk to blood borne 
pathogens (World Health Organization, 2002). The incidences of NSI have been reported mainly in the emergency room, especially during phlebotomy, intravenous line insertion and during intramuscular injection (Lachowicz et al., 2009). According to Centre for Disease Control and Prevention (CDC), in United States more than half of all sharps-related injuries are not reported (Risks and Prevention of Sharps Injuries in Healthcare Personnel, 2004). In the developing countries, people are at much higher risk due to the lack of reporting standards. In addition, poor knowledge and practices related to the risk and hazards of sharp injuries substantially contribute to the probability of the injuries (Sagoe et al., 2001). Common reasons found for the under reporting of sharp injuries may be that, failure to appreciate the potential consequences of such injuries, fear of disease, concern about losing the job and too much documentation and follow-up (Azadi et al., 2011).

The economic burden of these injuries cannot be ignored. Currently the cost of the post exposure management is borne by the health care administration, which includes Laboratory investigations, counselling and prophylactic treatment (Oh et al., 2013). Because of the financial burden many effective interventions to combat needle stick injuries have been suggested time-to-time like the recommendations to prevent improper needle manipulations, education, provision of sharps containers and introduction of safety engineered device (Tosini et al., 2010). The increased use of Single use devices such as disposable syringe, avoidance of re-capping of needles, proper segregation of Sharp waste in puncture proof containers have contributed significantly in reduction of the incidence of NSI. Guidelines from CDC, WHO, and other health authorities, emphasis on following universal precautions, safe injection and infusion practices, documentation and reporting of all occupational injuries, pre- and post-exposure prophylaxis to all heath care professionals coming in contact with blood and body fluids (National Accreditation Board for Hospitals and Healthcare Providers (NABH), 2015). This study was undertaken to know the prevalence, pattern of NSI in the selected tertiary care teaching hospital.

\section{Materials and Methods}

A retrospective assessment of all the NSI's from January to December 2014 from Father Muller Medical College Hospital, Kankanady, Mangalore, Karnataka, India. The data was collected during the pre accreditation period where the policies and protocols of infection control were formulated and getting implemented. The reports analysed consisted of the number of cases, date and time of occurrence, category of health care personnel's affected and the reason for the injury. The hospital followed standard protocol for the needle stick injury cases recommended by CDC.

\section{Results and Discussion}

A total of 70 cases, were reported during the study period. Among the reported needle stick injury cases reported, majority were female $80 \%$ (Figure1). Overall classification of the cases was done as staffs and trainee. It is clear from the (figure 2) that considerable number of students/ trainee (44\%) had sharp injuries. Needle stick injuries were more common among nursing professionals accounting for $50 \%$ of total needle stick injuries, followed by doctors $25 \%$ (figure 3). Most of injuries occurred in the wards (41\%), followed by by intensive care units and emergency department $(25 \%)$ (Figure 4). Around one fifth of the needle stick injuries occurred during phlebotomy procedure (Figure 5), the improper disposal of sharp and recapping also the cause for NSI accounting for 7\% each. 


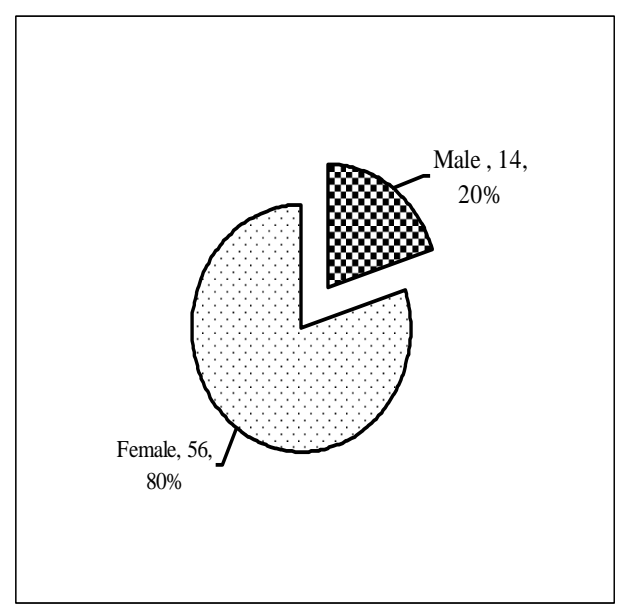

Fig.1 Gender distribution among needle stick injury cases.

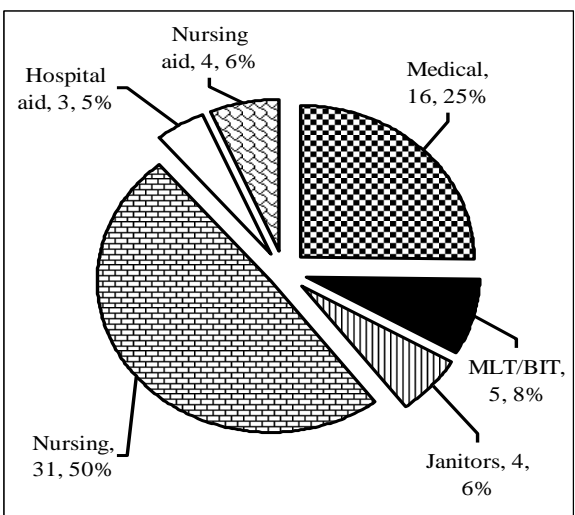

Fig 3. Proportion of professions in needle stick injury cases

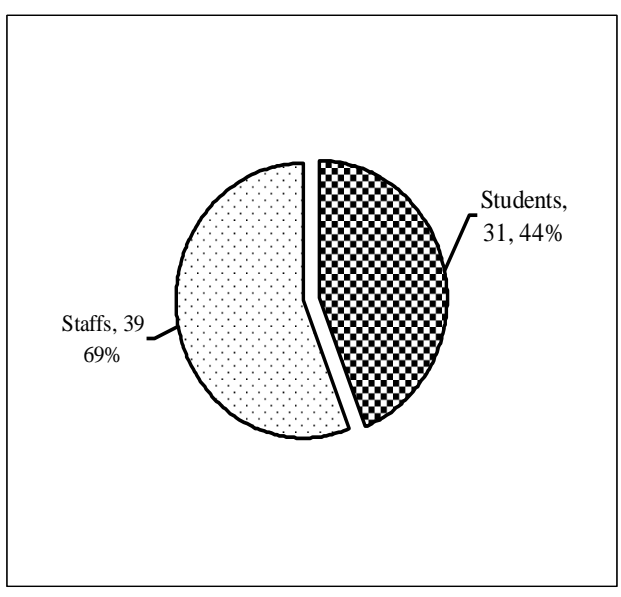

Fig .2 Needle stick injuries among staffs and students

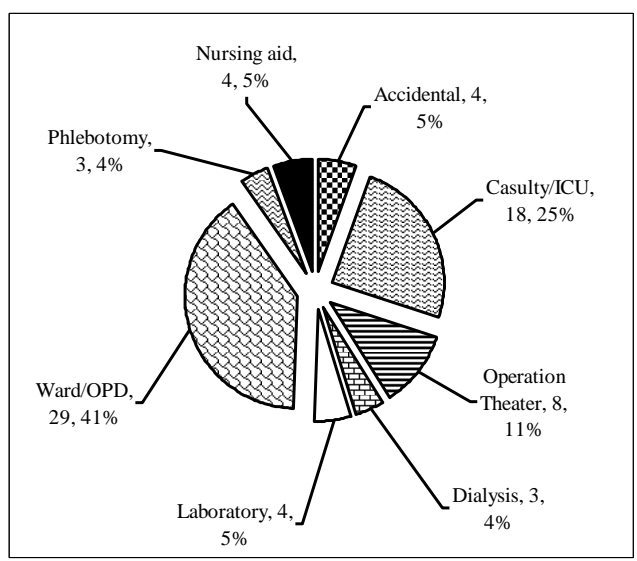

Fig 4. Needle stick injury incidents in different areas

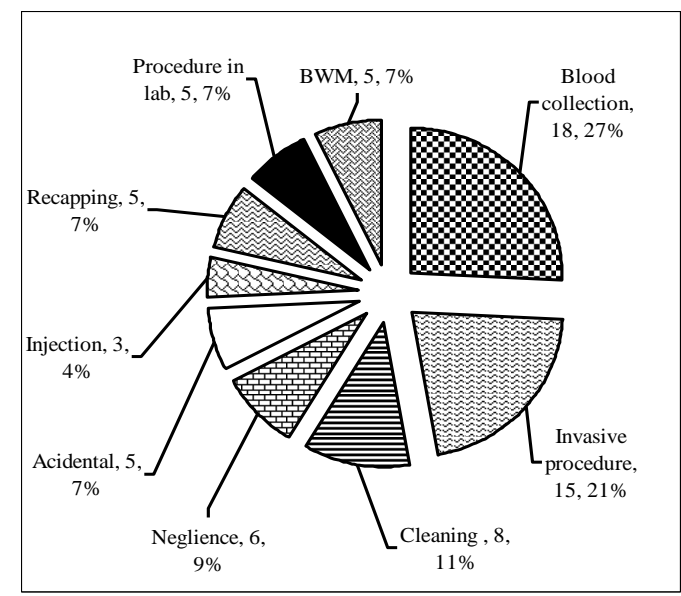

Fig. 5 Major causes of needle stick injuries

Along with contact and airborne transmission incidents, NSI's are among the most frequent health hazards for professional health care workers. In this study the gender ratio of the injured was considerably skewed toward female sex, with $80 \%$ of the injured being female, as 
the staff nurses, nursing aids, housekeeping staff are pre-dominantly female. Similar study results were seen in other parts of the country.

Considerable amount of NSI's were seen among the students/ trainee, $44 \%$ among which the most frequently affected are from nursing and medical fraternity. Prevalence of NSI's is high among the students (nurses and doctors) (Ghasemzadeh et al., 2015). Among medical students, the incidences of NSIs are more when they attend surgical departments than medical departments during their compulsory rotatory internship (Koenig et al., 1995; Birenbaum et al., 2002). Accidents are more common during the early period of their training/ internship which demands adequate training and sensitization (Siegmann et al., 2016).

In the hospital, most of the injections either intravenous or intramuscular, are administrated by the nurses, hence this category of the staff are at higher risk of NSI followed by doctors, if proper precautions are not taken while handling the injection syringe. The withdrawal of blood for arterial blood gas analysis which is the crucial and important investigation in the ICU was major cause for NSI in trainee doctors during the study period. This may be attributed to lack of precaution taken during the procedure. This emphasis that, there should be a proper hands-on training to all students of medical profession on handling sharps before they interact with patients so as to prevent NSI during handling the sharps. The laboratory technicians handle sharps during the procedures like Fine Needle Aspiration Cytology (FNAC) and recapping of needles in the lab is the cause for NSI. Even though, the nursing aids and the housekeeping staff do not handle sharp directly, the incidence of NSI is seen in them as the needle do not get segregated properly in puncture proof container and the left un attending, which make this category of staff to get the needles pricked into the skin during housekeeping and cleaning activities in the hospital.
The present study reported the circumstances that lead to the NSI's and then classified them under different categories. Incidence of NSI was high during the blood collection, both venous and arterial blood collection. Blood collection from in inadequately restrained restless patients and from paediatric patients are the leading cause of the NSI. A study reported that handling uncooperative patient and patient movement precipitated the occurrence of sharp injury in $22 \%$ and $20 \%$ of HCWs, respectively (Ruben $e t$ al., 1983).

NSI's also has been reported during the invasive procedures. Injuries mainly occurred during the suturing procedure especially when fingers were used and while transferring the sharps from one hand to another. The use of blunt suture needles in fascia and muscle closure and designated neutral zones (hands-free technique) (Stringer et al., 2002) are two strategies that have confirmed their efficacy in randomized clinical trials.

Substantial number of NSI's also occurred during cleaning due to the needles left unattended after the procedure, and not segregating the sharps in designated container. A study showed that every $10^{\text {th }}$ accident was caused by needles that were left in inappropriate places, regardless of the healthcare setting (Krasinski et al., 1987). Recapping of the needles was more common among students/ trainee and attributed to $7 \%$ of sharp injuries. Past studies of needle stick injuries have shown that $10 \%$ to $25 \%$ NSI's occurred when recapping a used needle and continues to be the common cause.

This study concludes that health care workers are at high risk of occupational exposure from sharp injuries along with student trainees. Adhering to standard guidelines, regular training for handling sharps and sensitizing the HCW's on blood borne infections are some of the best preventive strategies to prevent sharp injuries. In a teaching hospital, as number of trainee student get admitted on regular interval, induction training on universal precautions, 
infection control practices with emphasis on consequences and prevention of NSI needs to be taken regularly. Proper segregation of sharps and appropriate Post exposure prophylaxis needs to be monitored by the infection control unit of the hospital to eliminate the transmission of infection.

\section{References}

Ashat, M., Bhatia, V., Puri, S., Thakare, M., Koushal, V. 2011. Needle stick injury and HIV risk among health care workers in North India. Indian J. Med. Sci., 65(9): 371-8.

Azadi, A., Anoosheh, M., Delpisheh, A. 2011. Frequency and barriers of underreported needlestick injuries amongst Iranian nurses, a questionnaire survey. J. Clin. Nursing, 20: 488493.

Birenbaum, D., Wohl, A., Runyon, M., Stearns, B., and Willett, M. 2002. Medical students' occupational exposures to potentially infectious agents. Acad. Med., 77(2): 185-189.

CDC. National Institute for Occupational Safety and Health. NIOSH. Promoting a productive workplace through safety and health research. https://www.cdc.gov/niosh

Ghasemzadeh, I., Kazerooni, M., Davoodian, P., Hamedi, Y., Sadeghi, P. 2015. Sharp Injuries Among Medical Students. Glob. J. Health Sci., 7(5): 320-5.

Gillen, M., McNary, J., Lewis, J., et al. 2003. Sharpsrelated inj-uries in California Healthcare facilities. Pilot study re-sults from sharps injury surveillance registry. Infect. Control Hosp. Epidemiol., 24: 113121.

Hartley, J.E., Ahmed, S., Milkins, R., Naylor, G., Monson, J.R., Lee, P.W. 1996. Randomized trial of blunt-tipped versus cutting needles to reduce glove puncture during mass closure of the abdomen. $\mathrm{Br}$. J. Surg., 83: 1156-1157.

Koenig, S. and Chu, J. 1995. Medical student exposure to blood and infectious body fluids. Am. J. Infect. Control, 23: 40-43.

Krasinski, K., LaCouture, R., Holzman, R.S. 1987. Effect of changing needle disposal systems on needle puncture injuries. Infect. Control, 8(2): 5962.

Lachowicz, R., Matthews, P.A. 2009. The pattern of sharps injury to health care workers at Witbank Hospital. SA Fam. Pract., 51(2): 148-151.

National Accreditation Board for Hospitals and Healthcare Providers (NABH). Guide Book to Accreditation Standards for Hospitals (4th edition) 2015: 112-129.

National Institute for Occupational Safety and Health. 1999. NIOSH Alert: preventing needle stick injuries in health care settings [DHHS (NIOSH) Publication No. 2000-108] U.S. Department of Health and Human Services, Cincinnati, OH.

Oh, H.S., Yoon Chang, S.W., Choi, J.S., Park, E.S., Jin, H.Y. 2013. Costs of post exposure management of occupational sharps injuries in health care workers in the Republic of Korea. Am. J. Infect. Control, 41: 61-65.

Risks and Prevention of Sharps Injuries in Healthcare Personnel. 2004. CDC, Atlanta, Ga, USA.

Robson, L.S., Stephenson, C.M., Schulte, P.A., Amick, B.C., Irvin, E.L., Eggerth, D.E., et al. 2012. A systematic review of the effectiveness of occupational health and safety training. Scand J. Work Environ. Health, 38: 193-208.

Ruben, F.L., Norden, C.W., Rockwell, K., Hruska, E. 1983. Epidemiology of accidental needle-puncture wounds in hospital workers. Am. J. Med. Sci., 286(1): 26-30.

Sagoe, M.C., Pearson, R.D., Perry, J., Jagger, J. 2001. Risks to health care workers in developing countries. New England J. Med., 345: 538-41.

Siegmann, S., Muth, T., Kluth, W., Hofbauer, U., Angerer, P., Schwarze, S. 2016. Needlestick Injuries to Medical Students]. Gesundheitswesen, 78(1): 22-7.

Stringer, B., Infante-Rivard, C., Hanley, J. 2002. Effectiveness of the hands-free technique in reducing operating theatre injuries. Occup. Environ. Med., 59: 703-713.

Tosini, W., Ciotti, C., Goyer, F., et al. 2010. Needle stick injury rates according to different types of safety-engineered devices: results of a French multicenter study. Infect. Control Hosp. Epidemiol., 31: 402-407.

World Health Organization. The world health report: 2002: Reducing risks, promoting healthy life. World Health Organization, Geneva.

\section{How to cite this article:}

Ramakrishna Pai Jakribettu, Ovine Loyster D'souza, Valerian Sudeep Pinto, Vidya Rao Surlu, Rekha Boloor and Manjeshwar Shrinath Baliga. 2017. Needle Stick Injuries among Health Care workers in a Multispecialty Hospital: A Retrospective Study. Int.J.Curr.Microbiol.App.Sci. 6(5): 833-837.

doi: https://doi.org/10.20546/ijcmas.2017.605.093 